17 School of Mechanical and Manufacturing Engineering,

18 Dublin City University,

19 Dublin 9, Ireland.

20 tanya.levingstone@dcu.ie

21 Tel: $00353(0) 17007718$

22 Fax:00 $353(0) 17007148$ Ireland.

\title{
Application of Response Surface Methodology in the Design of Functionally Graded Plasma Sprayed Hydroxyapatite Coatings
}

\author{
Tanya J. Levingstone ${ }^{1,2,3}$, Niall Barron ${ }^{4}$, Malika Ardhaoui ${ }^{5}$, Khaled Benyounis ${ }^{1,2,3}$, \\ Lisa Looney ${ }^{1,2,3}$, Joseph Stokes ${ }^{1,2,3}$
}

${ }^{1}$ School of Mechanical and Manufacturing Engineering, Dublin City University, Dublin 9,

${ }^{2}$ Centre for Medical Engineering Research, Dublin City University, Dublin 9, Ireland

${ }^{3}$ National Centre for Plasma Science and Technology, Dublin City University, Dublin 9, Ireland ${ }^{4}$ National Institute for Cellular Biotechnology, Dublin City University, Glasnevin, Dublin

${ }^{5}$ Surface Engineering Research Group, School of Electrical, Electronic and Mechanical Engineering, University College Dublin, Belfield, Dublin 4, Ireland. 


\section{Abstract}

25 The highly complex process-property-structure relationship poses a major challenge in the optimization of plasma sprayed hydroxyapatite coatings. In addition, contradictions in relation to the ideal coating properties exist; a dense, highly crystalline coating is required for long term coating stability, whereas coatings with lower crystallinity dissolve more rapidly but have an improved osteogenic response in vivo. In this study, response surface methodology (RSM) is utilized to investigate the influences and interaction effects of current, gas flow rate, powder feed rate, spray distance and carrier gas flow rate on the roughness, crystallinity, purity, porosity and thickness of plasma sprayed HA coatings. Roughness related to the particle velocity and particle melting, and was highest at low gas flow rates and, due to the quadratic effect of current, at the central current value. High crystallinity resulted at high current and low spray distance due to the presence of bulk crystalline material and recrystallization of amorphous material. Purity was highest at low carrier gas flow rate and high gas flow rate, where particle temperature was reduced. Porosity was dependent on the degree of particle melting and was highest at low gas flow rate and powder feed rate and at high current and spray distance. Coating thickness was determined by the number of particles and the degree of flattening on impact, and was highest at high current, low gas flow rate, high powder feed rate and low spray distance. From this in-depth analysis, predictive process equations were developed and optimized to produce two distinct coatings; a stable coating and a bioactive coating, designed to form the base and surface layers of a functionally graded coating respectively, to provide enhanced osteogenesis, while maintaining long-term stability. Culture of osteoblast-like cells on the coatings demonstrated an increased osteogenic response on the bioactive coating compared to the other groups. Overall, this study identifies parameter effects and interactions leading to the development of optimized coatings with the potential to enhance the 47 functional life of HA coated implants in vivo. 


\section{Keywords}

49 Plasma spraying, hydroxyapatite, response surface methodology (RSM), functionally graded

50 coatings, in vitro response 
53 Hydroxyapatite (HA), a calcium phosphate bioceramic, has been widely used in orthopaedic and 54 dental applications as it has an almost identical chemical composition to that of the mineral component of bone and has proven osteoconductive properties [1,2]. One such application is as a coating for metallic hip implants, where it increases the rate of bone repair, provides enhanced fixation of the implant to human bone, and protects the body from any metal-ion release from the metallic implant $[3,4]$. Clinical results for HA coated implants demonstrate success in achieving earlier bone ingrowth and fixation [5]. Lazarinis et al. reported survival rates for HA coated implants of $98 \%$ at 10 years [6] and Sandiford et al. reported survival rates of $91.7 \%$ at 22.5 years [7]. Over time HA coatings are naturally resorbed by the body; however, delamination or rapid dissolution can result in implant failure [8-10]. Thus further improvements in HA coatings is necessary in order to achieve the goal of lifelong functionality.

The stability of HA coatings is largely dependent on crystallinity and purity [11]. Within the body, HA is degraded by two mechanisms, osteoclastic resorption and physiochemical dissolution [12]. These degradation processes negatively impact on the coating integrity leading to a weakened coating with a reduced functional life. However, coating degradation has positive impacts on bone formation, as dissolution of the coating leads to the release of calcium and phosphate ions, in the form of $\mathrm{Ca}^{2+}, \mathrm{H}_{2} \mathrm{PO}_{4-}, \mathrm{HPO}_{4}{ }^{2}, \mathrm{PO}_{4}^{3-}$ and $\mathrm{CaH}_{2} \mathrm{PO}^{4+}$, into the fluid surrounding the joint [10]. Proteins and ions activate the surface of the HA coating encouraging the precipitation of calcium and phosphate as HA crystals $[13,14]$. Additionally, previous studies have shown that calcium and phosphate released as a result of the degradation of calcium phosphate coatings can stimulate osteoblast responses leading to more rapid mineralization $[5,15]$. Thus in determining the optimal properties for calcium phosphate coatings, it is necessary to consider long term coating stability as 
well as the immediate osteogenic responses to the coating when implanted. This study proposes that a functionally graded coating containing two distinct layers, a stable base layer and a bioactive surface layer, provides the ideal solution in achieving a hydroxyapatite (HA) coating with enhanced bioactivity, while maintaining the long-term stability of the coated devices. Previous research into functionally graded HA coatings focused on achieving enhanced coating adhesion through the development of titanium/HA graded coatings [16,17]. This study presents a novel approach through the use of RSM to develop optimized stable and bioactive coatings that can be functionally graded to achieve an enhanced osteogenic response.

HA coatings are commonly deposited using atmospheric plasma spraying, a thermal spray process in which powder particles are melted in a high temperature plasma jet and propelled towards a substrate material to form a coating. This technique offers advantages including high coating adhesion strength and a rapid coating deposition rate [8]. The process is affected by a large number of process parameters and parameter interactions that are not fully understood or accounted for, and as a result numerous contradictions in relation to the parameter effects on coating properties are reported in the literature [18-23]. Thus in order to tailor the properties of the coating to meet specific requirements, a detailed understanding of process-property-structure relationship is required. Response surface methodology (RSM) consists of a collection of mathematical and statistical tools used for designing experiments [24]. Representing a step forward from one-at-atime analyses, the method enables identification of optimal process parameters while deducing interactive effects between process parameters. RSM approaches have been used to investigate a range of plasma sprayed coatings including alumina, titanium dioxide, zirconia, and aluminatitania [25-27] in addition to hydroxyapatite [21,22,28,29]. Our previous work examined the main effects of current, gas flow rate, powder feed rate, spray distance and carrier gas flow rate on the roughness, crystallinity and purity of plasma sprayed hydroxyapatite and identified parameter 
101 effects and desirable parameter ranges for plasma spraying of HA coatings [30]. On a mechanistic

102 level, each of these parameters we seen to ultimately influence two key aspects; the degree of

103 particle melting within the plasma jet and the velocity at which particles impact the substrate

104 surface. This study aims to bring about a clearer understanding of these complex relationships

105 through further investigation of the process-property-structure relationships for plasma sprayed

106 hydroxyapatite coatings and to develop process equations that will enable the development of

107 optimized coatings that will form the stable base layer and bioactive surface layer of a functionally

108 graded coating. The specific objectives of the study were to use RSM 1) to assess the effects of

109 five process parameters: current (A), gas flow rate (B), powder feed rate (C), spray distance (D)

110 and carrier gas flow rate (E), on the crystallinity, purity, roughness, porosity and thickness of

111 plasma sprayed hydroxyapatite coatings; key properties that influence coating stability and cellular

112 response upon implantation, 2) to develop predictive process equations that can identify the ideal

113 process parameters required to produce a stable coating which will form the base layer of the

114 functionally graded coating and a bioactive layer that will form the surface layer of the functionally

115 graded coating and 3) to assess the osteogenic response to the developed coatings in vitro.

\section{2. Experimental Methods}

\section{2.1. Experimental Design}

119 The parameters and levels investigated in this study were selected based on the findings of an initial

120 screening study of the process carried out by the authors [30]. The screening study analysed the

121 effects of five parameters, (A) current (amps), (B) gas flow rate (standard cubic feet per hour

$122(\mathrm{scfh})),(\mathrm{C})$ powder feed rate $(\mathrm{g} / \mathrm{min}),(\mathrm{D})$ spray distance $(\mathrm{mm})$ and $(\mathrm{E})$ carrier gas flow rate (scfh),

123 and found all five to significantly affect the investigated responses. All five parameters were thus

124 included in the RSM study. Two levels were selected for each parameter based on the findings of 
the screening study. A Central Composite Design (CCD) consisting of a $5^{-1}$ Fractional Factorial

126 Design (16 experiments), with the addition of ten star point experiments and five centre point

127 experiment to provide a measure of process stability and curvature, was used to investigate the

128 effects of the various process parameters on the properties of HA coatings. The study was designed

129 using the statistical software Design-Expert 7.0 (Stat-Ease Inc., Minneapolis, USA). The total

130 number of experimental runs for the design was 31 , as described in Table 1 . The experiments were

131 carried out in random order to remove the effects of systematic errors. Five coating responses were

132 examined: roughness, crystallinity, purity, porosity and thickness. The main effects on each

133 response were identified using the backward selection method to elimate insignificant terms (P-

134 value $\leq 0.01)$. The analysis of variance (ANOVA) test was used to determine the statistical

135 significance of the developed equations. Statistical measures, $\mathrm{R}^{2}$, adjusted $\mathrm{R}^{2}$, predicted $\mathrm{R}^{2}$ and

136 adequate precision, were used to determine the adequacy of the resultant equations.

\subsection{Materials}

139 Titanium alloy (Ti, Ti6Al4V, grade 5, Impact Ireland, Dublin, Ireland) discs, $10 \mathrm{~mm}$ in diameter

140 with a thickness of $2 \mathrm{~mm}$, were used as the substrate material in this study. Prior to spraying, discs

141 were grit-blasted at a pressure of 5 bar and an angle of incidence of $75^{\circ}$, using pure white $\mathrm{Al}_{2} \mathrm{O}_{3}$

142 grit with a particle size of $500 \mu \mathrm{m}$ (mesh 36). High pressure air was used to remove and surface

143 alumina particles and samples were then placed in dilute acetone in an ultrasonic cleaner for 5

144 minutes, rinsed in water and then dried. The average surface roughness (Ra) of the discs was 3.2

$145 \mu \mathrm{m}$, as measured using surface profilometry (Surftest 402, Mitutoyo, Michigan, US).

146 Hydroxyapatite $\left(\mathrm{HA}, \mathrm{Ca}_{10}\left(\mathrm{PO}_{4}\right)_{6}(\mathrm{OH})_{2}\right)$ powder with acrystallinity of $99.96 \%$ and purity of $99 \%$

147 was used (Captal 60-1 Thermal Spraying HA powder, Plasma Biotal, UK) [30]. The HA powder 
had an irregular morphology and the particle size fell within two separate clusters, between 0.1 and

$1491.0 \mu \mathrm{m}$ and between 10 and $100 \mu \mathrm{m}$, with a mean particle size of $38.3 \mu \mathrm{m}$ [30].

150

151

\subsection{Plasma Spraying}

152 Plasma spraying was carried out using the Sulzer Metco 9MB plasmatron, fitted with a 3M7-GH 153 nozzle, as previously described [30]. High purity argon was used as both the plasma forming gas

154 and the powder carrier gas and no secondary gas was used. A traverse speed of $38 \mathrm{~mm} / \mathrm{s}$ and a 155 spray time of $35 \mathrm{~s}$ were used for all coatings, resulting in 15 passes of the spray gun.

\subsection{Coating Characterisation}

158 Five parameters were investigated for each coating; roughness, crystallinity, purity, porosity and thickness. Surface roughness, Ra, was measured using the Surftest 402 surface profilometer

160 (Mitutoyo, Michigan, US). Measurements were repeated four times with the sample orientation changed between each measurement. The surface morphology of each coating was also examined using scanning electron microscopy (SEM) (LEO 440 Stereo Scan, Leica, UK). The crystallinity and purity of HA coatings were determined using x-ray diffraction (D-8 Advance Diffractometer,

164 Bruker, Coventry, UK) fitted with a copper anode. A locked-couple scan was carried out between 20 and $60^{\circ} 2 \theta$ and an increment of 0.02 and a scan speed of 5 sec/step were applied. The $\%$ crystallinity and \% purity were calculated in accordance with ASTM F 2024-00 [31] using the Diffract Plus EVA software (Bruker AXS, UK) as previously described [30]. In order to calculate coating porosity and thickness, samples were sectioned longitudinally and mounted in resin

169 (Beuhler Epoxide Resin and Epoxide Hardner, mixed at a resin to hardner ratio of 5:1). Samples were then ground and polished (Motopol 2000, Beuhler, Warwick, UK) and then cleaned in dilute acetone solution to remove any remaining polishing debris. Samples were imaged at a 
magnification of 20x for each specimen using the Reichert "MeF2" Universal Camera Optical

173 Microscope. Porosity measurements were carried out in accordance with the BSI standard 1071-5:

1741995 [32]. Porosity was calculated using the Omninet Enterprise image analysis software (Beuhler,

175 Warwick, UK). Greyscale images were thresholded using an automated routine in order to

176 determine the percentage porosity for each coating. The Omninet Enterprise image analysis

177 software was also used to determine the coating thickness. Six measurements were taken for each

178 coating and an average obtained.

179

\subsection{Assessment of model goodness of fit and optimization of process parameters}

181 Following the development of proess equations using the RMS, the model goodness of fit was 182 assessed using point prediction tests. Three new coatings were sprayed using parameters selected randomly by the Design Expert software, detailed in Table 3, and the response values predicted by

184 the process equations were compared to the actual measured response values. The $\%$ error betweeen the predicted and actual values was obtained. Optimization of process parameters was conducted using the Design Expert software by combining numerical simulation coupled with the

187 desirability function. The constraints applied in order to produce a stable coating and bioactive coating and the identified optimal parameter settings for each are summarised in Table 4. These settings were identified based on the desired roughness, crystallinity, purity, porosity and thickness values from previous literature. The optimised coatings were then fabricated and characterised and the results were compared to the values predicted by the developed process equations.

\subsection{In vitro assessment}

194 In vitro analysis was carried out to determine the osteoblast response to the optimized stable and 195 bioactive HA coatings in comparison to an uncoated Ti disc. MG-63 human osteoblast-like cells 
196 (LGC Promochem, Middlesex, UK) were cultured in standard growth medium (Eagle's minimum

197 essential medium, supplemented with $10 \%$ fetal bovine serum, $1 \%$ non-essential amino acids, $1 \%$

198 glutamine, $1 \%$ sodium pyruvate and $1 \%$ pen-strep) at $37^{\circ} \mathrm{C}$ and $5 \% \mathrm{CO}_{2}$. The $\mathrm{Ti}$ and $\mathrm{HA}$-coated

199 discs were sterilized using dry heat at $160^{\circ} \mathrm{C}$ for 3 hours and placed in 24 -well plates, prior to 200 seeding cells on the surface of the discs at a density of 10,000 cells per disc. Cell proliferation and 201 cell viability were analyzed at 7, 14, 21 and 28 day timepoints and gene expression was analyzed 202 at 7,21 and 28 day timepoints. At each timepoint, cells were detached from the disc surface using 203 trypsin and then counted using a haemacytometer and a phase contrast microscope following trypan 204 blue exclusion.

\subsubsection{RNA Extraction and Quantifiation}

207 The expression of extracellular matrix (ECM) mineralization markers in MG-63 cells on the three 208 surfaces was determined by RNA extraction and quantitative real time PCR. Cells were lysed and 209 total RNA was isolated at each time point using the RNeasy Mini kit (Qiagen, UK). Total RNA 210 concentrations were determined spectrophotometrically at a wavelength of $260 \mathrm{~nm}$ on a 211 Nanodrop ${ }^{\mathrm{TM}}$.

\subsubsection{Quantitative Real-Time PCR}

214 The effect of the coating surfaces on the expression of alkaline phosphatase (ALP), type 1 collagen 215 (COL1) and osteocalcin (OC) was evaluated at each time point (Taqman, Applied Biosystems, 216 UK). Relative gene expression was carried out using the 7500 Fast Real-Time PCR System 217 (Applied Biosystems, Thermofisher Scientific, UK). Detection was achieved using Sybr Green 218 which is excited at $490 \mathrm{~nm}$ and emits at $520 \mathrm{~nm}$. During the PCR reaction, samples were subjected 219 to an initial denaturation phase at $95^{\circ} \mathrm{C}$ for $20 \mathrm{~s}$ followed by 40 cycles of denaturation at $95^{\circ} \mathrm{C}$ for 
$2203 \mathrm{~s}$ and annealing and extension at $60^{\circ} \mathrm{C}$ for $30 \mathrm{~s}$. Glyceraldehyde phosphate dehydrogenase 221 (GAPDH) was used as the endogenous control.

\subsubsection{Statistical Analysis}

224 Statistical analysis for cell culture work was carried out using One-Way Anova to determine 225 significance (SigmaStat 3.0, Systat Software Inc., California, US). A p-value of $<0.05$ represented 226 a significant difference.

\section{Results}

\subsection{Measured Responses}

230 The measured responses for each experimental run (N1-N31) are presented in Table 1. The average 231 roughness $(\mathrm{Ra})$ ranged between $3.1 \mu \mathrm{m}$ and $9.6 \mu \mathrm{m}$. SEM micrographs of cross-sections the 232 coatings with the lowest roughness (N11) and highest roughness (N30) are shown in Fig. 1(a) and 233 Fig. 1(b). The average crystallinity ranged between $71.2 \%$ and $85 \%$ and the average purity ranged 234 between $93.8 \%(\mathrm{~N} 13)$ and $99.3 \%(\mathrm{~N} 12)$ as shown in Table 1. Overall, all coatings met the $>45$ $235 \%$ crystallinity and > $95 \%$ purity required by ISO 13779-2:2000 (Implants for surgery236 Hydroxyapatite. Coatings of hydroxyapatite) [33]. The average coating porosity ranged between $2376.8 \%(\mathrm{~N} 8)$ and $59.1 \%$ (N10). SEM micrographs of the surfaces of coatings N8 and N10 and shown 238 in Fig. 1(c) and Fig. 1(d) and cross-sections of the coatings N8 and N10 are shown in Fig 1(e) and 239 Fig. 1(f). The average coating thickness ranged from $17.2 \mu \mathrm{m}$ to $543.5 \mu \mathrm{m}$. SEM micrographs of 240 cross-sections of the coatings for the lowest (N3) and highest (N6) thickness coatings are shown in 241 Fig 1(g) and Fig 1(h). The results were used to generate process equations, summarized in Table 242 2. Statistical measures for each parameter, also summarised in Table 2, indicate that there is a good 
243 fit between the data and the equation for each response. The overall parameter effects for 244 roughness, crystallinity, purity, porosity and thickness are summarized in the perturbation plots in 245 Fig. 2.

247 3.2. Influence of process parameters on roughness

248 Roughness was found to be significantly affected by two parameters, current (A) and gas flow rate 249 (B), and one interation, between current and gas flow rate $\left(\mathrm{A}^{*} \mathrm{~B}\right)$, as shown in Table 2 ( $\mathrm{P}$-value $\leq$ 250 0.01). Gas flow rate (B) has the greatest influence, this was a linear relationship with increasing 251 gas flow rate leading to a reduction in roughness. Current (A) was also seen to influence the coating 252 roughness, a quadratic relationship was observed with higher currents leading to higher roughness 253 values as can be seen in Fig. 3. The curvature of the current and roughness relationship indicates 254 the roughness increases with increasing current up to a current of about $650 \mathrm{~A}$, after which the 255 roughness decreases again. The relative influence of these parameters on coating roughness is 256 summarised in the perturbation plot in Fig. 2(a). The resultant regression equation for roughness is 257 presented in Table 2 using actual parameters and coded parameters (where -1 and 1 represent the 258 low and high levels).

\subsection{Influence of process parameters on crystallinity}

261 Crystallinity was found to be affected by current (A), gas flow rate (B), spray distance (D) and 262 carrier gas flow rate (E). In addition, three interactions have an effect; current and gas flow rate (A $263 * \mathrm{~B})$, current and spray distance $(\mathrm{A} * \mathrm{D})$, and gas flow rate and carrier gas flow rate $(\mathrm{B} * \mathrm{E})$. 264 Crystallinity was highest when the current was high, and gas flow rate, spray distance and carrier 265 gas flow rate were all low as shown in Fig. 3. The relative influence of these parameters on coating 
crystallinity is summarised in the perturbation plot in Fig. 2(b). The resultant regression equation

267 for crystallinity is presented in Table 2 using actual parameters and coded parameters.

3.4. Influence of process parameters on purity

The purity of the coating was found to be influenced by current (A), gas flow rate (B), powder feed rate $(C)$, spray distance $(D)$ and carrier gas flow rate $(E)$. Gas flow rate, carrier gas flow rate and spray distance had the greatest effects with higher purity resulting when gas flow rate was high and carrier gas flow rate and spray distance were low as shown in Fig. 4. The relative influence of these parameters on coating purity is summarised in the perturbation plot in Fig. 2(c). The resultant 275 regression equation for purity is presented in Table 2 using actual parameters and coded 276 parameters.

\subsection{Influence of process parameters on porosity}

279 Coating porosity is influenced by current, gas flow rate, powder feed rate and spray distance. Gas 280 flow rate and powder feed rate had the greatest effect with higher levels of porosity resulting at low 281 gas flow rate and low powder feed rate as shown in Fig. 5. The relative influence of these 282 parameters on coating porosity is summarised in the perturbation plot in Fig. 2(d). The resultant 283 regression equation for porosity is presented in Table 2 using actual parameters and coded 284 parameters.

287 Coating thickness was influenced by all parameters, with current and gas flow rate having the 288 greatest effect. Thicker coatings resulted at high current, high powder feed rate, high carrier gas 
289 flow rate and low gas flow rate and spray distance as shown in Fig. 6. The relative influence of 290 these parameters on coating thickness is summarised in the perturbation plot in Fig. 2(e). The 291 resultant regression equation for thickness is presented in Table 2 using actual parameters and 292 coded parameters.

294 3.7. Point prediction tests and process optimization

295 The point prediction tests demonstrate that the developed equations for each response accurately 296 predict the actual measured response values (Table 3). The percentage error between the predicted 297 and actual responses is very low $(<5 \%)$ for crystallinity, purity and roughness. The average 298 percentage error for the porosity and thickness equations was found to be higher $(<11.5 \%)$ than 299 for the other three responses. This is expected as the model statistics indicated that these equations 300 have lower predictive power than the other equations developed as a result of the inherant 301 variability identified within these responses in the centre point experimental runs. The percentage 302 error found is still low enough to conclude that the model can predict the response value achieved. 303 By applying the constraints identified in Table 4, the plasma spray process was optimized to 304 produce two distinct coating with different properties depending on the optimization criteria used. 305 The spray parameters used for each coating, the predicted and actual values for each response and 306 percentage error are presented in Table 4Table 5.

\subsection{In vitro assessment}

\subsubsection{Cell proliferation and viability}

310 Biocompatibility was assessed by quantifying cell number and cell viability on the uncoated Ti, 311 the stable coating and the bioactive coating. MG-63 osteoblast-like cells were seen to readily 
312 proliferate on all surfaces with cell numbers seen to increase over the 28 day time period, thus

313 indicating the biocompatibility of the surfaces under investigation. There was a trend towards

314 higher cell numbers in the uncoated Ti group than the stable coating and bioactive coating groups

315 at each timepoint although this was not significant (Fig.7(a)). High levels of cell viability were

316 observed on all surfaces across all time points as shown in Fig.7(b), with no significant differences

317 in viability observed between the groups.

\subsubsection{Gene Expression Analysis}

320 The expression of extracellular matrix mineralization markers type 1 collagen (COL1), alkaline 321 phosphatase (ALP) and osteocalcin (OC) were determined using quantitative RT-PCR analysis. 322 COL1, an early marker of mineralization which is expressed during cellular proliferation, was expressed by the MG-63 cells on each surface as shown in Fig. 8(a). At day 7, the highest level of COL1 expression is observed on the titanium surface. Expression of COL1 peaked at day 21, approximately a 2 fold increase was observed in all groups, with expression levels highest in the stable coating group. ALP, expressed during the osteoblast maturation stage, was highest in all groups at day 7, with higher levels observed in the HA coated groups compared to the uncoated Ti group. The expression of ALP for each surface at each time point is shown in Fig. 8(b). At day 28 no expression of ALP was observed on the stable coating or uncoated Ti groups; however, low levels of ALP expression were observed in the bioactive coating group. OC, expressed during the mineralization stage, was seen to be higher on the bioactive coating compared to the stable coating or uncoated $\mathrm{Ti}$, with a 3.5 fold increase observed in this group at day 7 . This demonstrates that the bioactive coating led to much earlier mineralization than the other groups. By day 21 , OC expression was seen to be similar in all groups with expression levels remaining higher in the 
osteocalcin on each surface is shown in Fig. 8(c). This indicates that higher levels of mineralization occurred in the bioactive coating group than in the other groups.

\section{Discussion}

340 A major challenge exists in the design of optimized hydroxyapatite coated implants for dental and 341 orthopaedic applications. On one hand, for long term coating stability, a dense highly pure, highly 342 crystalline coating is required [34]; on the other hand, dissolution of the coating surface has been 343 shown to lead to an improved in vivo response, resulting in an increase in the rate of bone formation 344 [14]. This study used response surface methodology (RSM) to investigate the influences and 345 interaction effects of current, gas flow rate, powder feed rate, spray distance and carrier gas flow 346 rate on the roughness, crystallinity, purity, porosity and thickness of plasma sprayed HA coatings 347 and demonstrated that all process parameters investigated significantly effect the properties of the 348 resultant HA coatings. Process equations with high predictive power were developed in order to 349 identify the ideal process parameters required to produce a stable coating and a bioactive coating, 350 designed to be applied sequentially to form the base layer and surface layer respectively of a 351 functionally graded coating.

353 The roughness of the fabricated HA coatings ranged from $3.1 \mu \mathrm{m}$ and $9.5 \mu \mathrm{m}$ and was influenced 354 by current and gas flow rate with an interaction effect between current and gas flow rate. The results 355 show that a lower gas flow rate increases particle melting due to an increased residence time within 356 the plasma jet and thus particles undergo a greater degree of flattening on impact with the substrate 357 leading to a lower coating roughness. The quadratic nature of the roughness response to current is 358 clearly identified here bringing new clarity to previous conflicting findings [22,23,30,35]. The 359 particle size distribution within the HA powder also likely has an important influence in this study, 
with particle sizes falling within two separate clusters, between 0.1 and $1.0 \mu \mathrm{m}$ and between 10 and

$361100 \mu \mathrm{m}[30]$. Thus at low current and high gas flow rate, the plasma jet is cooler and only smaller 362 particles are melted thus the coating roughness is lower. At low gas flow rate, and a current of up 363 to $650 \mathrm{~A}$ the number of larger particles being melted increases and thus the roughness increases.

364 After 650 A the degree of melting of the particles being deposited increases and the particles are 365 more molten and thus undergo a greater degree of flattening on impact. As can be observed from the micrographs in Fig. 1, the high roughness coating is much thicker than the low roughness 367 coating, thus verifying that under the high roughness condition much greater numbers of particles coating dissolution and thus enable an enhanced osteogenic response as previously reported.

Coating crystallinity varied between $71.8 \%$ and $85.2 \%$, and was highest at high current, low gas flow rate, low spray distance and low carrier gas flow rate. Importantly, coating crystallinity in all cases was $>45 \%$ which is the requirement for biomedical applications [38]. The crystalline the HA particles and HA that has recrystallised following spraying [39]. Thus coating crystallinity is dependant on the degree of particle melting and the particle cooling rate. It can be seen from the interaction effects that high coating crystallinity results at high current, low gas flow rate and low spray distance. These conditions cause an increase in particle melting and an increase in substrate temperature, leading to a low particle cooling rate. The quantity of larger particles deposited is 
resulting in a high $\%$ crystallinity. The low spray distance causes particle melting to be low due to reduced residence time in the plasma jet. At low spray distance the substrate temperature is high as it is closer to the plasma jet and thus cooling rate is low. The carrier gas flow rate determines the entry positions of particles into the jet. At a low carrier gas feed rate particles do not enter the center of the plasma jet, and as a result undergo less melting. In optimising coatings, crystallinity was succcessfully maximised in the stable layer and minimised in the bioactive layer as coating dissolution rates have been shown to be dependant on coating crystallinity [11].

The purity of the resultant coatings coating purity was found to vary between $96.1 \%$ and $99.7 \%$ and thus all coatings had purities of $>95 \%$ as required for medical devices [38]. From the interaction plots it is clear that coating purity is dependent on the residence time of particles within the plasma jet. As a result, purity is higher when the gas flow rate is high and the spray distance is low and thus the particles spend less time in the plasma jet and remain at a lower temperature. Cizek and Khor [22] previously investigated the relationship between HA particle in-flight temperature and velocity and the loss of the HA phase in the resultant coatings and were not able to identify any correlations. The findings in this study verify the relationship between phase changes and particle melting proposed by Sun et al. [23]. The position of the particles within the plasma jet also impacts on the coating purity, thus at low carrier gas flow rate fewer HA powder particles enter the hotter centre region of the plasma jet and thus particle temperature remains lower. In coating optimization, the resultant stable coating had a purity of $98.1 \%$ whereas the bioactive coating had a purity of $96.1 \%$. Coatings with higher purity have previously been shown to have lower dissolution rates [11].

Porosity was found to vary between $6.8 \%$ and $59.1 \%$. The porosity of a coating is dependent on the degree of particle melting within the plasma jet and the amount of spreading on impact with 
the substrate. Partially melted particles do not flatten completely, leaving gaps between them,

411 resulting in a more porous coating. A highly molten particle that impacts the substrate at high speed 412 spreads to a greater degree on the substrate thus reducing porosity [41]. Thus while a number of 413 competing effects can be observed in the interaction plots, the overall effects in the perturbation 414 plot show that porosity was highest at low gas flow rate, as this would result in lower particle 415 impact velocity, and low powder feed rate, where less particles are deposited with each pass and 416 thus a greater number of gaps exist between particles. Higher porosity also results at high current 417 and high spray distance as a greater number of the larger particles are melted within the plasma jet 418 under these conditions. These findings confirm the findings of Kweh et al. [20], who observed an 419 increase in HA coating porosity at increased spray distances. Cizek and Khor [22] further 420 investigated the relationship between porosity and in-flight velocity and temperature, however no 421 significant trend was observed. A low porosity of $8.9 \%$ was successfully achieved in the stable coating with the aim of improving the mechanical stability of the coating [20]. Increased porosity of $47.3 \%$ was achieved in the bioactive coating, designed to allow a greater surface area for cell attachment and coating dissolution and to an enhanced osteogenic response following implantation as previously reported $[34,42,43]$.

Coating thickness was found to range between $17.2 \mu \mathrm{m}$ and $543.5 \mu \mathrm{m}$ with thicker coating resulting at high current, low gas flow rate, high powder feed rate, low spray distance and high carrier gas flow rate. Coating thickness is known to be related to the number of particles that are deposited on the substrate surface and also the degree of flattening of the particles on impact, thus coating thickness also provides a measure deposition efficiency. The number of particles that are deposited on the substrate relates to the amount of particles that are fed into the plasma jet, the number of particles that are sufficiently melted within the jet to adhere to the substrate on impact and the number of particles that maintain sufficient velocity to remain in the plasma jet until the point of 
impact. As expected, thicker coatings resulted at higher powder feed rates. Thicker coating also

resulted at high current and low spray distance under these conditions more particles are melted within the plasma jet and the deposition efficiency is higher. Thicker coatings also result at low gas flow rate and high powder feed rate and carrier gas feed rate. Under these conditions greater numbers of particles enter the plasma jet leading to an increase in the number of particles deposited on the substrate. A similar relationship between coating thickness and particle melting has been reported by Sun et al. [23]. In the optimization process, coating thickness was successfully maximized for both coatings resulting in a thickness of $391.4 \mu \mathrm{m}$ for the stable coating and 232.5 $\mu \mathrm{m}$ for the bioactive coating.

The assessment of the cellular response to the optimized stable and bioactive coatings using MG63 osteoblast-like cells demonstrated an enhanced osteogenic response in the bioactive coating group compared to the stable coating and uncoated Ti control groups. Cells were seen to readily proliferate on all surfaces, indicating that all surfaces were biocompatible. Although not significant, there is a trend towards higher levels of proliferation on the Ti surface to the 28 day timepoint while on the HA coatings, lower levels of proliferation are observed, thus indicating that the cells in the HA coating groups may enhance the matrix maturation or matrix mineralization phases of osteoblast differentiation. There is no significant difference in the expression of earlier markers of osteogenesis, collagen (COL1) and alkaline phosphatase (ALP), between the three groups. Previous studies have shown that ALP expression was not affected by roughness [42], or HA purity or calcium to phosphate $(\mathrm{Ca} / \mathrm{P})$ ratio $[44]$. A significant difference in osteocalcin $(\mathrm{OC})$ expression was observed at day 7 and day 28 with highest levels observed on the bioactive coating. Osteocalcin is a marker of the mineralization phase of osteoblast differentiation and thus this indicates that the bioactive coating promotes mineralization earlier than the titanium surface or stable coating. It is noted that OC expression is higher in the Ti group than the stable coating group. This may be due 
460 to the surface roughness of the $\mathrm{Ti}$ disc; enhanced osteogenesis on roughened $\mathrm{Ti}$ alloys has 461 previously been reported [45]. It is recognized that rapid osseointegration is crucial in order for an 462 implant to be successful in vivo, thus these results indicate that the bioactive coating provides the 463 most favorable conditions for bone formation. While this study indicates that the osteogenic 464 properties of the bioactive coating are enhanced compared to the uncoated Ti and the stable HA 465 coating, further in vitro analysis would be beneficial in order to fully elucidate the mechanisms 466 involved. These novel coatings also hold potential for the local delivery of advanced therapeutics 467 including drugs and biomolecules, designed to enhance osteoinduction, or antibiotics agents, 468 designed to prevent infection post implantation. Taken together these results demonstrate that 469 through process optimization the compositional and microstructural properties of plasma sprayed 470 hydroxyapatite coatings can be tailored to achieve coatings with increased stability, designed for 471 long term functionality, or with enhanced osteogenic properties and an ability to biologically 472 instruct and stimulate the regeneration of bone tissue at the implant site.

\section{5. Conclusions}

474 This study successfully used response surface methodology to identify the effects of current gas 475 flow rate, powder feed rate, spray distance, and carrier gas flow rate, on the crystallinity, purity, 476 roughness, porosity and thickness of plasma sprayed hydroxyapatite coatings; key properties that 477 influence coating stability and cellular response upon implantation. Consistent and competing 478 influences are identified enabling predictive process equations to be developed and optimized to 479 produce two distinct coatings, a stable coating and bioactive coating, designed to form the base and 480 surface layers respectively of a functionally graded coating. Through in vivo analysis enhanced 481 osteogenic response to the bioactive coating was demonstrated. The optimized coatings have the 482 potential to stimulate osteogenesis at the implant site and to enhance the functional life of HA 483 coated implants in vivo 


\section{Acknowledgements}

486 The author would like to acknowledge the research support provided by the Irish Research Council 487 for Science, Engineering and Technology, funded by the National Development Plan.

\section{References}

490

\section{Reference List}

492 [1] R.Z. LeGeros, Properties of osteoconductive biomaterials: calcium phosphates. Clin. Orthop. 493395 (2002) 81-98.

494 [2] R.Z. LeGeros, Calcium phosphate-based osteoinductive materials, Chem. Rev. 108 (2008) 495 4742-4753.

496 [3] S. Sousa, M. Barbosa, Effect of hydroxyapatite thickness on metal ion release from Ti6Al4V 497 substrates, Biomaterials. 17 (1996) 397-404.

498 [4] L. Sun, C.C. Berndt, K.A. Khor, H. Cheang, K.A. Gross, Surface characteristics and 499 dissolution behavior of plasma-sprayed hydroxyapatite coating, J. Biomed. Mater. Res. 62 (2002) $500 \quad 228-236$.

501 [5] S. Vahabzadeh, M. Roy, A. Bandyopadhyay, S. Bose, Phase stability and biological property 502 evaluation of plasma sprayed hydroxyapatite coatings for orthopedic and dental applications, 503 Acta biomaterialia. 17 (2015) 47-55.

504 [6] S. Lazarinis, J. Kärrholm, N.P. Hailer, Effects of hydroxyapatite coating on survival of an 505 uncemented femoral stem: a Swedish Hip Arthroplasty Register study on 4,772 hips, Acta 506 orthopaedica. 82 (2011) 399-404.

507 [7] N. Sandiford, C. Doctor, S.S. Rajaratnam, S. Ahmed, D.J. East, K. Miles, A. Butler-Manuel, 508 J.A. Shepperd, Primary total hip replacement with a Furlong fully hydroxyapatite-coated titanium 509 alloy femoral component: Results at a minimum follow-up of 20 years, Bone Joint J. 95-B (2013) $510 \quad 467-471$.

511 [8] L. Sun, C.C. Berndt, K.A. Gross, A. Kucuk, Material fundamentals and clinical performance 512 of plasma-sprayed hydroxyapatite coatings: a review, J. Biomed. Mater. Res. 58 (2001) 570-592.

513 [9] M. Nagano, T. Nakamura, T. Kokubo, M. Tanahashi, M. Ogawa, Differences of bone 514 bonding ability and degradation behaviour in vivo between amorphous calcium phosphate and 515 highly crystalline hydroxyapatite coating, Biomaterials. 17 (1996) 1771-1777. 
[10] F. Fazan, P. Marquis, Dissolution behavior of plasma-sprayed hydroxyapatite coatings, J.

517 Mater. Sci. Mater. Med. 11 (2000) 787-792.

518 [11] P. Ducheyne, S. Radin, L. King, The effect of calcium phosphate ceramic composition and 519 structure on in vitro behavior. I. Dissolution, J. Biomed. Mater. Res. 27 (1993) 25-34.

520 [12] J.R. Davis, Handbook of Materials for Medical Devices, ASM International, Ohio, 2003.

521 [13] J. Weng, Q. Liu, J. Wolke, X. Zhang, K. De Groot, Formation and characteristics of the 522 apatite layer on plasma-sprayed hydroxyapatite coatings in simulated body fluid, Biomaterials. 18 (1997) 1027-1035.

[14] J. Morgan, K.R. Holtman, J.C. Keller, C.M. Stanford, In vitro mineralization and implant calcium phosphate-hydroxyapatite crystallinity. Implant Dent. 5 (1996) 264-271.

[15] J. De Bruijn, C. Van Blitterswijk, J. Davies, Initial bone matrix formation at the hydroxyapatite interface in vivo, J. Biomed. Mater. Res. 29 (1995) 89-99.

528

529

530

531

532

533

534

535

536

537

538

539

540

541

542

543

544

545

546

547

548

549

550

[16] C. Chen, T. Huang, C. Kao, S. Ding, Characterization of functionally graded hydroxyapatite/titanium composite coatings plasma-sprayed on Ti alloys, Journal of Biomedical Materials Research Part B: Applied Biomaterials. 78 (2006) 146-152.

[17] K. Khor, Y. Gu, C. Quek, P. Cheang, Plasma spraying of functionally graded hydroxyapatite/Ti-6Al-4V coatings, Surface and Coatings Technology. 168 (2003) 195-201.

[18] R. Gadow, A. Killinger, N. Stiegler, Hydroxyapatite coatings for biomedical applications deposited by different thermal spray techniques, Surface and Coatings Technology. 205 (2010) $1157-1164$.

[19] G.A. Fielding, M. Roy, A. Bandyopadhyay, S. Bose, Antibacterial and biological characteristics of silver containing and strontium doped plasma sprayed hydroxyapatite coatings, Acta biomaterialia. 8 (2012) 3144-3152.

[20] S. Kweh, K. Khor, P. Cheang, Plasma-sprayed hydroxyapatite (HA) coatings with flamespheroidized feedstock: microstructure and mechanical properties, Biomaterials. 21 (2000) 12231234.

[21] J. Cizek, K.A. Khor, Z. Prochazka, Influence of spraying conditions on thermal and velocity properties of plasma sprayed hydroxyapatite, Materials Science and Engineering: C. 27 (2007) 340-344.

[22] J. Cizek, K.A. Khor, Role of in-flight temperature and velocity of powder particles on plasma sprayed hydroxyapatite coating characteristics, Surface and Coatings Technology. 206 (2012) 2181-2191.

[23] L. Sun, C.C. Berndt, C.P. Grey, Phase, structural and microstructural investigations of plasma sprayed hydroxyapatite coatings, Materials Science and Engineering: A. 360 (2003) 7084. 
[24] C. Pierlot, L. Pawlowski, M. Bigan, P. Chagnon, Design of experiments in thermal spraying: A review, Surface and Coatings Technology. 202 (2008) 4483-4490.

[25] T. Steeper, D. Varacalle, G. Wilson, W. Riggs, A. Rotolico, J. Nerz, A design of experiment study of plasma-sprayed alumina-titania coatings, J. Therm. Spray Technol. 2 (1993) 251-256.

[26] B. Lin, M. Jean, J. Chou, Using response surface methodology for optimizing deposited partially stabilized zirconia in plasma spraying, Appl. Surf. Sci. 253 (2007) 3254-3262.

[27] S. Forghani, M.J. Ghazali, A. Muchtar, A.R. Daud, N. Yusoff, C.H. Azhari, Effects of plasma spray parameters on $\mathrm{TiO} 2$-coated mild steel using design of experiment (DoE) approach, Ceram. Int. 39 (2013) 3121-3127.

[28] N. Khun, Z. Li, K. Khor, J. Cizek, Higher in-flight particle velocities enhance in vitro tribological behavior of plasma sprayed hydroxyapatite coatings, Tribol. Int. 103 (2016) 496-503.

[29] S. Dyshlovenko, L. Pawlowski, P. Roussel, D. Murano, A. Le Maguer, Relationship between plasma spray operational parameters and microstructure of hydroxyapatite coatings and powder particles sprayed into water, Surface and Coatings Technology. 200 (2006) 3845-3855.

[30] T.J. Levingstone, M. Ardhaoui, K. Benyounis, L. Looney, J.T. Stokes, Plasma sprayed hydroxyapatite coatings: Understanding process relationships using design of experiment analysis, Surface and Coatings Technology. 283 (2015) 29-36.

[31] Standard Practice for X-ray determination of phase content of plasma-sprayed hydroxyapatite coatings", ASTM F 2024-00, ASTM International. (2000).

[32] Advanced technical ceramics-Methods of test for ceramic coatings: Part 5: Determination of porosity, DD ENV 1071-5:1995, British Standards Institute. (1995).

[33] Implants for surgery- Hydroxyapatite. Coatings of hydroxyapatite, ISO 13779-2:2000 (2000).

[34] R.B. Heimann, Thermal spraying of biomaterials, Surface and Coatings Technology. 201 (2006) 2012-2019.

[35] K. Gross, M. Babovic, Influence of abrasion on the surface characteristics of thermally sprayed hydroxyapatite coatings, Biomaterials. 23 (2002) 4731-4737.

[36] D.O. Costa, P.D. Prowse, T. Chrones, S.M. Sims, D.W. Hamilton, A.S. Rizkalla, S.J. Dixon, The differential regulation of osteoblast and osteoclast activity by surface topography of hydroxyapatite coatings, Biomaterials. 34 (2013) 7215-7226.

[37] R. Reid, B. Hall, I. Marriott, A. El-Ghannam, Early osteoblast responses to orthopedic implants: Synergy of surface roughness and chemistry of bioactive ceramic coating, Journal of Biomedical Materials Research Part A. 103 (2015) 1961-1973. 
584 [38] Standard Specification for Composition of Ceramic Hydroxyapatite for Surgical Implants, 585 ASTM F1185-03, ASTM International. (2003).

586 [39] T. Kim, Q. Feng, Z. Luo, F. Cui, J. Kim, Highly adhesive hydroxyapatite coatings on 587 alumina substrates prepared by ion-beam assisted deposition, Surface and Coatings Technology. 58899 (1998) 20-23.

589 [40] Implants for surgery- hydroxyapatite. Part 1: Ceramic hydroxyapatite, BS ISO 13779590 1:2000, International Organisation for Standards. (2000).

591 [41] C. Quek, K. Khor, P. Cheang, Influence of processing parameters in the plasma spraying of 592 hydroxyapatite/Ti-6Al-4V composite coatings, J. Mater. Process. Technol. 89 (1999) 550-555.

593 [42] D.D. Deligianni, N.D. Katsala, P.G. Koutsoukos, Y.F. Missirlis, Effect of surface roughness 594 of hydroxyapatite on human bone marrow cell adhesion, proliferation, differentiation and 595 detachment strength, Biomaterials. 22 (2000) 87-96.

596 [43] M. Rouahi, E. Champion, P. Hardouin, K. Anselme, Quantitative kinetic analysis of gene 597 expression during human osteoblastic adhesion on orthopaedic materials, Biomaterials. 27 (2006) 598 2829-2844.

599 [44] S. Best, B. Sim, M. Kayser, S. Downes, The dependence of osteoblastic response on 600 variations in the chemical composition and physical properties of hydroxyapatite, J. Mater. Sci. 601 Mater. Med. 8 (1997) 97-103.

602 [45] E. Chikarakara, P. Fitzpatrick, E. Moore, T. Levingstone, L. Grehan, C. Higginbotham, M. 603 Vázquez, K. Bagga, S. Naher, D. Brabazon, In vitro fibroblast and pre-osteoblastic cellular 604 responses on laser surface modified Ti-6Al-4V, Biomedical Materials. 10 (2014) 015007.

605

606 


\section{Tables}

Table 1: Response surface methodology design showing levels of the variables under investigation and the average values of the measured responses.

\begin{tabular}{|c|c|c|c|c|c|c|c|c|c|c|c|}
\hline \multirow[b]{2}{*}{ Key } & \multirow[b]{2}{*}{$\begin{array}{c}\text { Exp } \\
\text { Name } \\
\end{array}$} & \multicolumn{5}{|c|}{ Variables } & \multicolumn{5}{|c|}{ Responses (Average Values) } \\
\hline & & $\begin{array}{l}\mathbf{A} \\
A\end{array}$ & $\begin{array}{c}\text { B } \\
\text { slpm/scfh }\end{array}$ & $\begin{array}{c}\mathbf{C} \\
g / \mathrm{min}\end{array}$ & $\begin{array}{c}\mathbf{D} \\
\mathrm{mm}\end{array}$ & $\begin{array}{c}\mathbf{E} \\
\text { slpm/scfh }\end{array}$ & $\begin{array}{c}\text { Roughness } \\
\mu m\end{array}$ & $\begin{array}{c}\text { Crystallinity } \\
\%\end{array}$ & $\begin{array}{c}\text { Purity } \\
\%\end{array}$ & $\begin{array}{c}\text { Porosity } \\
\%\end{array}$ & $\begin{array}{c}\text { Thickness } \\
\mu m\end{array}$ \\
\hline \multirow{16}{*}{$\begin{array}{c}\text { Fractional } \\
\text { Factorial } \\
\text { Experiment } \\
\text { Runs }\end{array}$} & N1 & 550 & $42 / 90$ & 10 & 70 & $9.4 / 20$ & 8.1 & 73.3 & 96.4 & 19.2 & 94 \\
\hline & $\mathrm{N} 2$ & 750 & $42 / 90$ & 10 & 70 & $4.7 / 10$ & 8.7 & 82.7 & 99 & 24 & 375.4 \\
\hline & N3 & 550 & $71 / 150$ & 10 & 70 & $4.7 / 10$ & 4 & 72.5 & 99.1 & - & 17.2 \\
\hline & $\mathrm{N} 4$ & 750 & $71 / 150$ & 10 & 70 & $9.4 / 20$ & 7.6 & 81 & 98.5 & 16.3 & 265.4 \\
\hline & N5 & 550 & $42 / 90$ & 20 & 70 & $4.7 / 10$ & 8.8 & 80.4 & 97.6 & 12.7 & 286.1 \\
\hline & N6 & 750 & $42 / 90$ & 20 & 70 & $9.4 / 20$ & 8.8 & 79.7 & 97.8 & 6.9 & 543.5 \\
\hline & N7 & 550 & $71 / 150$ & 20 & 70 & $9.4 / 20$ & 5.7 & 72.4 & 98.3 & 29.5 & 85.4 \\
\hline & N8 & 750 & $71 / 150$ & 20 & 70 & $4.7 / 10$ & 7.7 & 85 & 98.6 & 6.8 & 182.8 \\
\hline & N9 & 550 & $42 / 90$ & 10 & 100 & $9.4 / 20$ & 8.1 & 82.3 & 96.8 & 34.4 & 122.4 \\
\hline & N10 & 750 & $42 / 90$ & 10 & 100 & $9.4 / 20$ & 8 & 73.8 & 95.4 & 59.1 & 153.5 \\
\hline & N11 & 550 & $71 / 150$ & 10 & 100 & $9.4 / 20$ & 3.1 & 74.2 & 97.1 & - & 30.2 \\
\hline & N12 & 750 & $71 / 150$ & 10 & 100 & $4.7 / 10$ & 5.5 & 71.2 & 99.3 & 6.8 & 48 \\
\hline & N13 & 550 & $42 / 90$ & 20 & 100 & $9.4 / 20$ & 8.4 & 76.5 & 93.8 & 16.7 & 137.3 \\
\hline & N14 & 750 & $42 / 90$ & 20 & 100 & $4.7 / 10$ & 8.5 & 80.1 & 97.1 & 36.2 & 346.2 \\
\hline & N15 & 550 & $71 / 150$ & 20 & 100 & $4.7 / 10$ & 4.2 & 73.2 & 98.8 & - & 17.4 \\
\hline & N16 & 750 & $71 / 150$ & 20 & 100 & $9.4 / 20$ & 8.1 & 79.6 & 97.3 & 11.2 & 211.7 \\
\hline \multirow{8}{*}{$\begin{array}{l}\text { Star Point } \\
\text { Runs }\end{array}$} & N17 & 550 & $57 / 120$ & 15 & 85 & $7.1 / 15$ & 6.8 & 78.3 & 97.8 & 11.6 & 42.6 \\
\hline & N18 & 750 & $57 / 120$ & 15 & 85 & $7.1 / 15$ & 7.9 & 80.3 & 98.9 & 12.3 & 320.2 \\
\hline & N19 & 650 & $42 / 90$ & 15 & 85 & $7.1 / 15$ & 7.5 & 80.4 & 97.1 & 30.2 & 276.2 \\
\hline & N20 & 650 & $71 / 150$ & 15 & 85 & $7.1 / 15$ & 8.5 & 79.4 & 97.9 & 15.7 & 52.5 \\
\hline & $\mathrm{N} 21$ & 650 & $57 / 120$ & 10 & 85 & $7.1 / 15$ & 7.3 & 81.1 & 97.9 & 23.5 & 193.4 \\
\hline & $\mathrm{N} 22$ & 650 & $57 / 120$ & 20 & 85 & $7.1 / 15$ & 5.8 & 81.8 & 97 & 9.7 & 271.5 \\
\hline & $\mathrm{N} 23$ & 650 & $57 / 120$ & 15 & 70 & $7.1 / 15$ & 8.8 & 76.9 & 98.3 & 29.7 & 300.8 \\
\hline & $\mathrm{N} 24$ & 650 & $57 / 120$ & 15 & 100 & $7.1 / 15$ & 8.9 & 77.4 & 97.3 & 11.3 & 104.2 \\
\hline
\end{tabular}




\begin{tabular}{|c|c|ccccc|ccccc|} 
& N25 & 650 & $57 / 120$ & 15 & 85 & $4.7 / 10$ & 7.6 & 74.1 & 98.4 & 8 & 114.8 \\
& N26 & 650 & $57 / 120$ & 15 & 85 & $9.4 / 20$ & 9.5 & 76.7 & 98.3 & 36.7 & 246.2 \\
& N27 & 650 & $57 / 120$ & 15 & 85 & $7.1 / 15$ & 7.6 & 76.5 & 97.8 & 29.2 & 213.6 \\
Centre & N28 & 650 & $57 / 120$ & 15 & 85 & $7.1 / 15$ & 8.1 & 78.9 & 97.5 & 12.8 & 194 \\
Point & N29 & 650 & $57 / 120$ & 15 & 85 & $7.1 / 15$ & 6.8 & 74.7 & 97.4 & 15.2 & 211.7 \\
Experiment & N30 & 650 & $57 / 120$ & 15 & 85 & $7.1 / 15$ & $\mathbf{9 . 6}$ & 80 & 97.8 & 10.9 & 309.7 \\
Runs & N31 & 650 & $57 / 120$ & 15 & 85 & $7.1 / 15$ & 7.2 & 76.2 & 97.8 & 24.2 & 193.2 \\
& N31 &
\end{tabular}

Table 2: Coded and actual experimental equations for roughness, crystallinity, purity, porosity and thickness. In the coded factor equations $\mathbf{- 1}$ and 1 represent the low and high levels.

\begin{tabular}{|c|c|c|c|c|c|c|c|c|}
\hline \multirow[b]{2}{*}{ Response } & \multirow[b]{2}{*}{ Coded and Actual Regression Equations } & \multirow[b]{2}{*}{ Eqn. No. } & \multicolumn{6}{|c|}{ Statistical Measures } \\
\hline & & & $\mathbf{R}^{2}$ & $\begin{array}{c}\text { Adjusted } \\
\mathbf{R}^{\mathbf{2}}\end{array}$ & $\begin{array}{c}\text { Predicted } \\
\mathbf{R}^{2}\end{array}$ & $\begin{array}{l}\text { Adequate } \\
\text { Precision }\end{array}$ & $\begin{array}{c}\text { F- } \\
\text { Value }\end{array}$ & p-value \\
\hline \multirow[b]{2}{*}{ Roughness } & Roughness $=+7.95+0.86 * \mathrm{~A}-1.27 * \mathrm{~B}+0.71 * \mathrm{~A} * \mathrm{~B}-0.84 * \mathrm{~A}^{2}$ & Eqn. 1 & \multirow[t]{2}{*}{0.74} & \multirow[t]{2}{*}{0.7} & \multirow[t]{2}{*}{0.63} & \multirow[t]{2}{*}{14.12} & \multirow[t]{2}{*}{18.28} & \multirow[t]{2}{*}{$<0.0001$} \\
\hline & $\begin{array}{l}\text { Roughness }=-9.73718+0.089639 * \text { current }-0.19524 * \text { gas flow } \\
\text { rate }+2.35417 \mathrm{E}-004 * \text { current } * \text { gas flow rate }-8.40598 \mathrm{E}-005 * \\
\text { current }^{2}\end{array}$ & Eqn. 2 & & & & & & \\
\hline \multirow[b]{2}{*}{ Crystallinity } & $\begin{array}{l}\text { Crystallinity }=+77.69+1.10 * \mathrm{~A}-1.57 * \mathrm{~B}-1.56 * \mathrm{D}-1.21 * \mathrm{E}+ \\
1.21 * \mathrm{~A} * \mathrm{~B}-2.19 * \mathrm{~A} * \mathrm{D}+1.50 * \mathrm{~B} * \mathrm{E}\end{array}$ & Eqn. 3 & \multirow[t]{2}{*}{0.75} & \multirow[t]{2}{*}{0.67} & \multirow[t]{2}{*}{0.54} & \multirow[t]{2}{*}{12.65} & \multirow[t]{2}{*}{9.64} & \multirow[t]{2}{*}{$<0.0001$} \\
\hline & $\begin{array}{l}\text { Crystallinity }=58.23267+0.086458 * \text { current }-0.46512 * \text { gas flow } \\
\text { rate }+0.84421 * \text { spray distance }-1.44222 * \text { carrier gas flow rate }+ \\
0.000404167 * \text { current } * \text { gas flow rate }-1.45833 \mathrm{E}-003 * \text { current } * \\
\text { spray distance }+0.01 * \text { gas flow rate } * \text { carrier gas flow rate }\end{array}$ & Eqn. 4 & & & & & & \\
\hline
\end{tabular}




\begin{tabular}{|c|c|c|c|c|c|c|c|c|}
\hline \multirow[b]{2}{*}{ Purity } & $\begin{array}{l}\text { Purity }=+98.37+0.12 * A+0.52 * \mathrm{~B}-0.081 * \mathrm{C}-0.37 * \mathrm{D}-0.55 \\
* \mathrm{E}-0.12 * \mathrm{~A} * \mathrm{D}-0.13 * \mathrm{~B} * \mathrm{C}+0.35 * \mathrm{~B} * \mathrm{D}-0.17 * \mathrm{D} * \mathrm{E}\end{array}$ & Eqn. 5 & \multirow[t]{2}{*}{0.91} & \multirow[t]{2}{*}{0.87} & \multirow[t]{2}{*}{0.77} & \multirow[t]{2}{*}{22.42} & \multirow[t]{2}{*}{25.72} & \multirow[t]{2}{*}{$<0.0001$} \\
\hline & $\begin{array}{l}\text { Purity }=97.68237+6.00833-3 * \text { Current }-0.014327 * \text { gas flow rate } \\
-0.021512 * \text { spray distance }+0.029722 * \text { carrier gas flow rate }- \\
0.0000603125 * \text { Current } * \text { spray distance }-0.000760714 * \text { gas flow } \\
\text { rate * powder feed rate }+0.00050625 * \text { gas flow rate } * \text { spray } \\
\text { distance }-1.74375 \mathrm{E}-003 * \text { spray distance } * \text { carrier gas flow rate }\end{array}$ & Eqn. 6 & & & & & & \\
\hline \multirow[b]{2}{*}{ Porosity } & $\begin{array}{l}\text { Porosity }=+19.20+1.18 * \mathrm{~A}-6.58 * \mathrm{~B}-5.81 * \mathrm{C}-0.76 * \mathrm{D}-4.12 \\
* \mathrm{~A} * \mathrm{~B}+7.12 * \mathrm{~A} * \mathrm{D}-10.17 * \mathrm{~B} * \mathrm{D}\end{array}$ & Eqn. 7 & \multirow[t]{2}{*}{0.68} & \multirow[t]{2}{*}{0.57} & \multirow[t]{2}{*}{0.42} & \multirow[t]{2}{*}{12.47} & \multirow[t]{2}{*}{6.08} & \multirow[t]{2}{*}{0.0007} \\
\hline & $\begin{array}{l}\text { Porosity }=-15.52858-0.22733 * \text { current }+2.59389 * \text { gas flow rate }- \\
1.16269 * \text { powder feed rate }-0.42552 * \text { spray distance }-1.37202 \mathrm{E}- \\
003 * \text { current } * \text { spray distance }-0.022605 * \text { gas flow rate } * \text { spray } \\
\text { distance }\end{array}$ & Eqn. 8 & & & & & & \\
\hline \multirow[b]{2}{*}{ Thickness } & $\begin{array}{l}\text { Thickness }=+190.19+89.67 * \mathrm{~A}-79.11 * \mathrm{~B}+43.46 * \mathrm{C}-50.81 * \\
\mathrm{D}+14.26 * \mathrm{E}-27.02 * \mathrm{~A} * \mathrm{D}-26.95 * \mathrm{~B} * \mathrm{C}+33.07 * \mathrm{~B} * \mathrm{E}\end{array}$ & Eqn. 9 & \multirow[t]{2}{*}{0.87} & \multirow[t]{2}{*}{0.82} & \multirow[t]{2}{*}{0.71} & \multirow[t]{2}{*}{19.13} & \multirow[t]{2}{*}{18.66} & \multirow[t]{2}{*}{$<0.0001$} \\
\hline & $\begin{array}{l}\text { Thickness }=-888.26428+2.42781 * \text { current }-3.24889 * \text { gas flow } \\
\text { rate }+30.25178 * \text { powder feed rate }+8.32107 * \text { spray distance }- \\
23.60044 * \text { carrier gas flow rate }-0 . .18013 * \text { current } * \text { spray } \\
\text { distance }-0.17966 * \text { gas flow rate } * \text { powder feed rate }+0.22044 * \\
\text { gas flow rate } * \text { carrier gas flow rate }\end{array}$ & Eqn. 10 & & & & & & \\
\hline
\end{tabular}


Table 3: Parameter settings for prediction point tests and model goodness of fit results

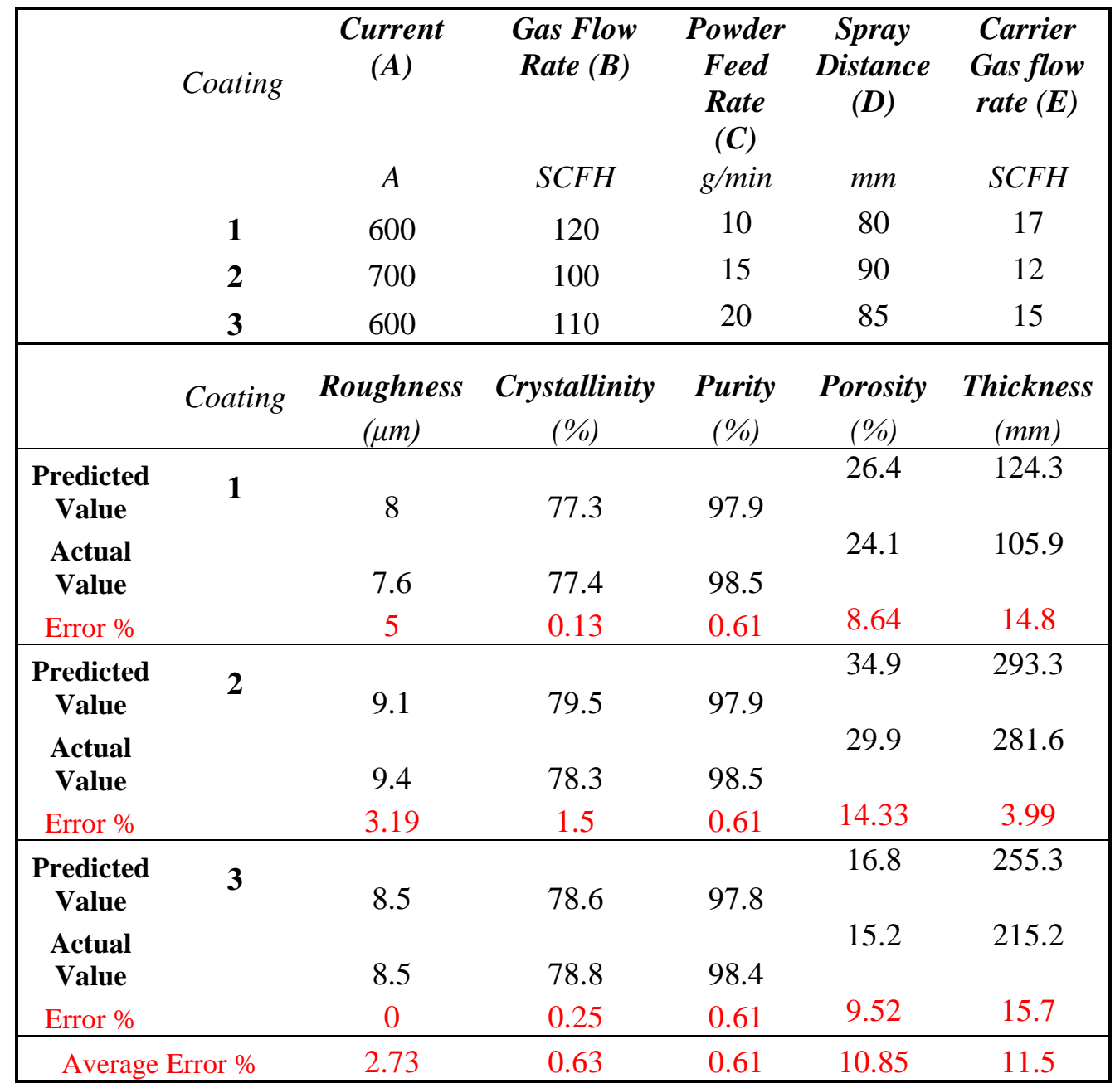




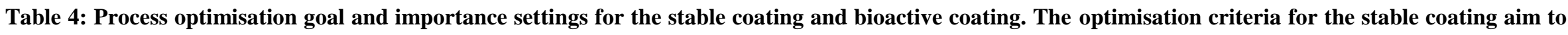

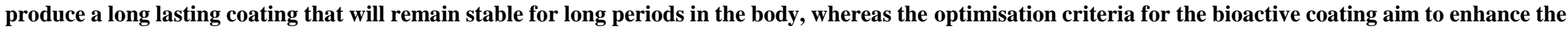
osteogenic response in vivo.

\begin{tabular}{|l|c|c|c|c|}
\hline & \multicolumn{2}{|c|}{$\begin{array}{c}\text { Stable Coating } \\
\text { Goal }\end{array}$} & \multicolumn{2}{c|}{$\begin{array}{c}\text { Bioactive Coating } \\
\text { Goal }\end{array}$} \\
& Maximize & +++ & Maximize & +++ \\
\hline Roughness $(\boldsymbol{\mu m})$ & Maxtance \\
\hline Crystallinity $(\%)$ & Maximize & +++++ & Minimize & +++++ \\
\hline Purity $(\%)$ & Maximize & ++++ & Minimize & +++++ \\
\hline Porosity $(\%)$ & Minimize & ++++ & Maximize & +++++ \\
\hline Thickness $(\boldsymbol{\mu m})$ & Maximize & + & Maximize & + \\
\hline
\end{tabular}

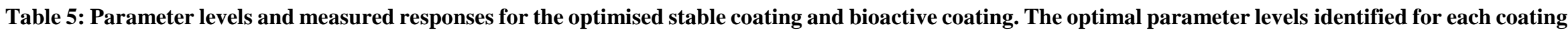
are presented with the predicted and actual values for each response and percentage error.

\begin{tabular}{|c|c|c|c|c|c|}
\hline \multicolumn{6}{|c|}{ Stable Coating } \\
\hline Parameter & & Response & Predicted & Actual & $\%$ Error \\
\hline Current $(A)$ & 750 & Roughness $(\mu \mathrm{m})$ & 8.6 & 8.3 & 3.5 \\
\hline Gas Flow Rate $(\operatorname{slpm} / s c f h)$ & $49.9 / 104.8$ & Crystallinity (\%) & 84.7 & 84.4 & 0.3 \\
\hline Powder Feed Rate $(\mathrm{g} / \mathrm{min})$ & 20 & Purity $(\%)$ & 98.5 & 98.1 & 0.4 \\
\hline Spray Distance $(\mathrm{mm})$ & 70 & Porosity $(\%)$ & 6.3 & 8.9 & 29.1 \\
\hline Carrier Gas flow rate $(\mathrm{slpm} / \mathrm{scfh})$ & $4.7 / 10$ & Thickness $(\mu \mathrm{m})$ & 414 & 391.4 & 5.4 \\
\hline \multicolumn{6}{|c|}{ Bioactive Coating } \\
\hline Parameter & & Response & Predicted & Actual & $\%$ Error \\
\hline Current $(A)$ & 750 & Roughness $(\mu \mathrm{m})$ & 8.9 & 9.1 & 2.4 \\
\hline Gas Flow Rate $($ slpm $/ s c f h)$ & $42.5 / 90$ & Crystallinity (\%) & 72.7 & 74.6 & 2.5 \\
\hline Powder Feed Rate $(\mathrm{g} / \mathrm{min})$ & 10.2 & Purity $(\%)$ & 95.7 & 96.1 & 0.4 \\
\hline Spray Distance $(\mathrm{mm})$ & 100 & Porosity (\%) & 53 & 47.3 & 10.8 \\
\hline Carrier Gas flow rate $(\mathrm{slpm} / \mathrm{scfh})$ & $9.4 / 20$ & Thickness $(\mu \mathrm{m})$ & 266.4 & 232.5 & 12.7 \\
\hline
\end{tabular}




\section{Figure captions}

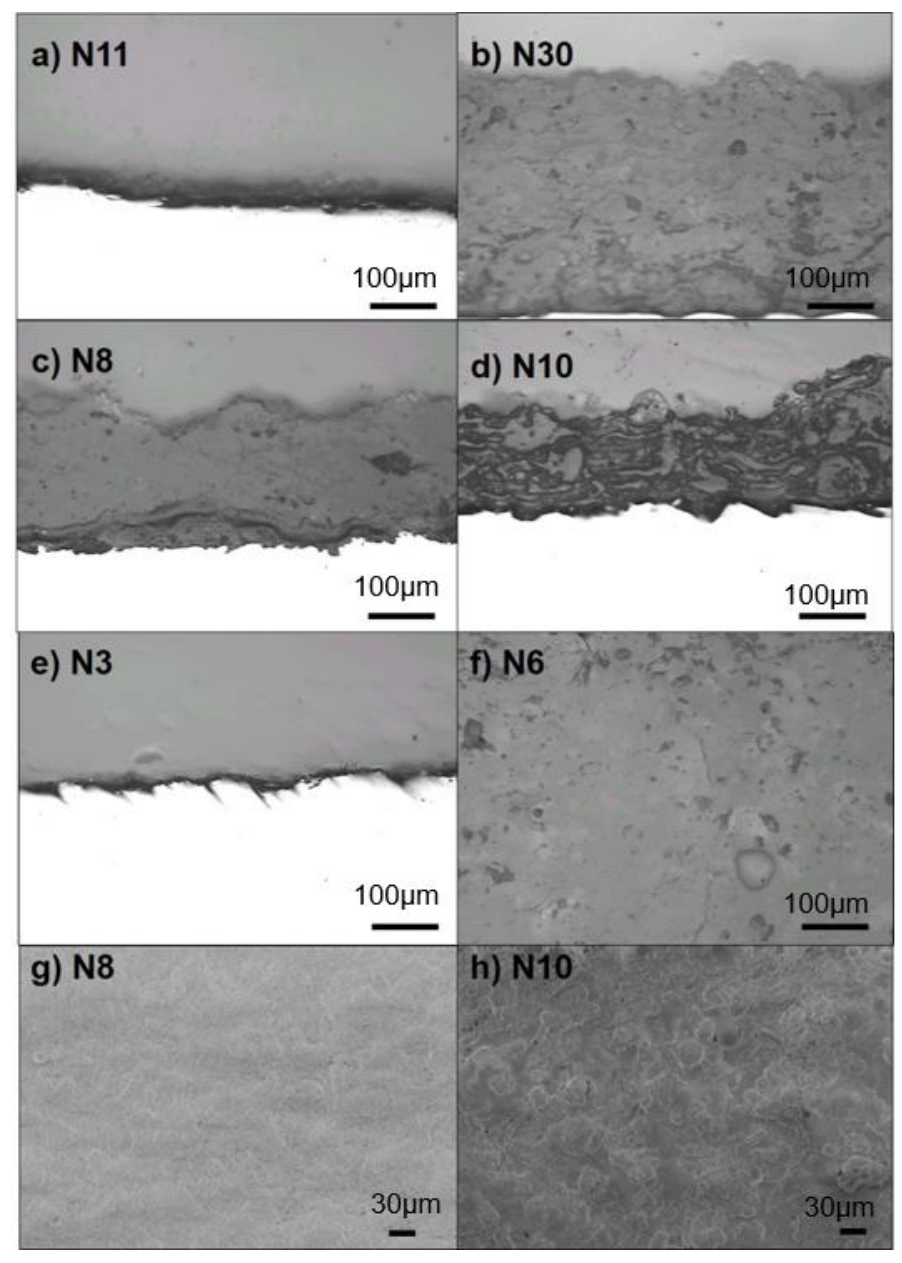

Figure 1: SEM micrographs showing the cross-sectional images of the coatings with the a) the lowest roughness (N 11) and b) the highest roughness (N30), c) the lowest porosity (N8) and d) the highest porosity (N10) e) the lowest thickness (N3) and f) the highest thickness (N6) and SEM micrographs of the surface of the coatings with the g) lowest porosity (N8) and h) highest porosity (N10). Scale bars for (a) to (f) represent $100 \mu \mathrm{m}$ and for (g) and (h) represent $30 \mu \mathrm{m}$ 

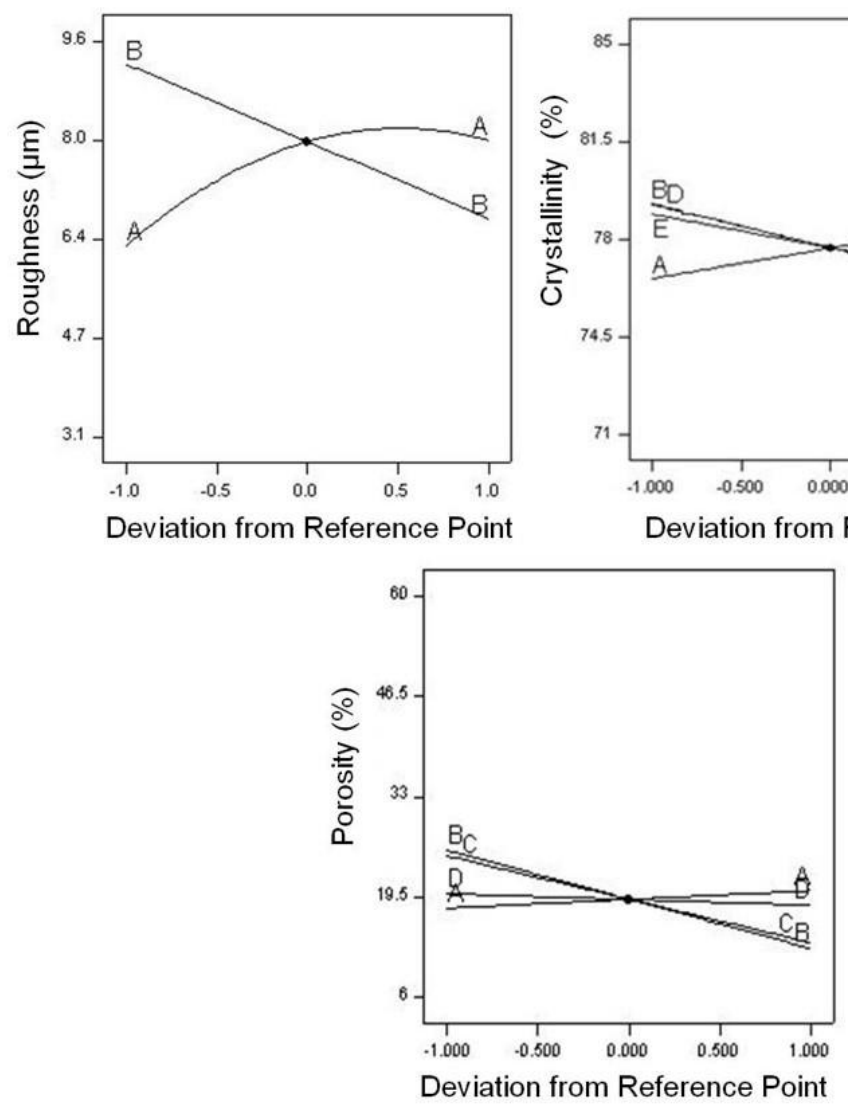
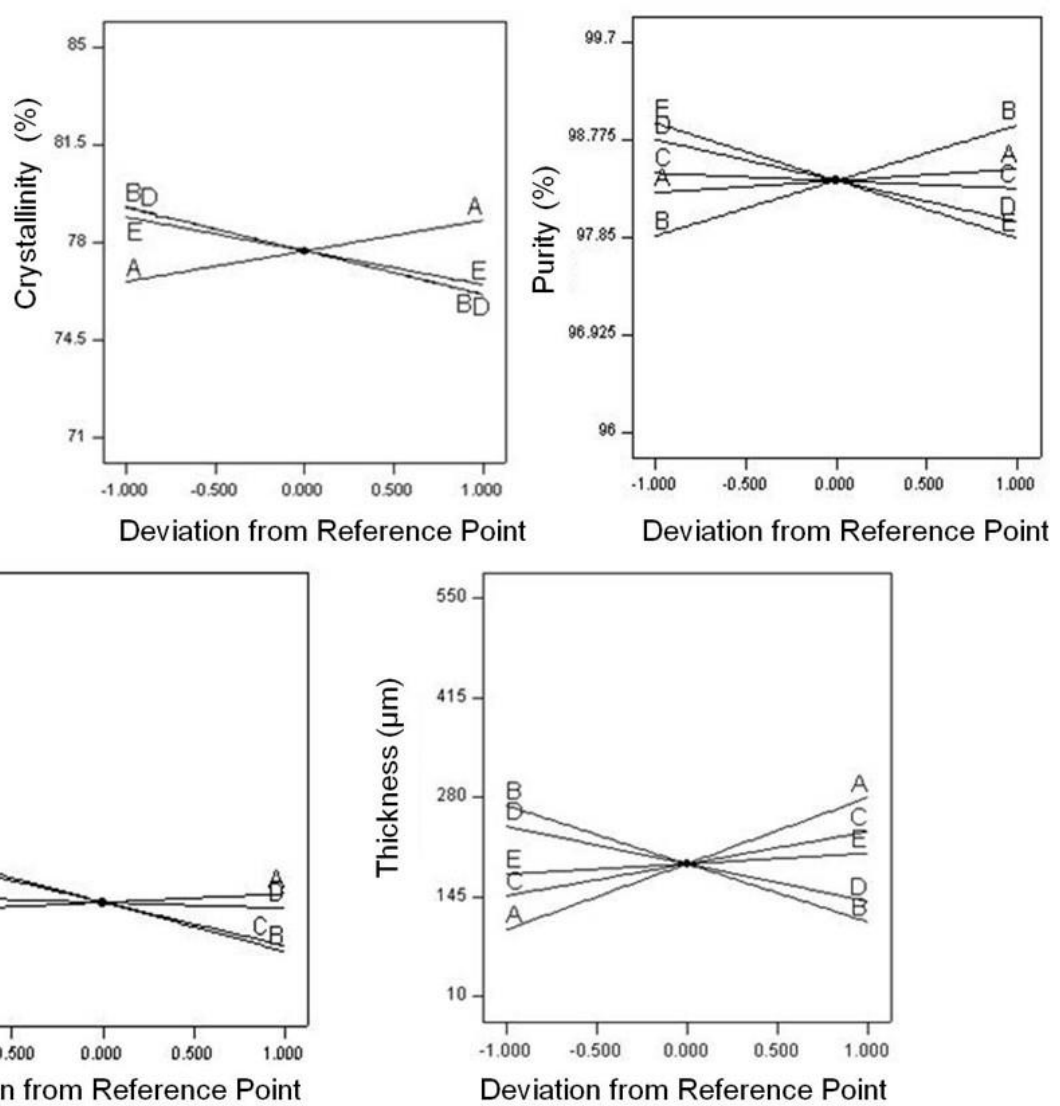

Figure 2: Perturbation plots showing the main effects of Current (A), Gas Flow Rate (B), Powder Feed Rate (C), Spray Distance (D) and Carrier Gas Flow Rate (E) on a) roughness, b) crystallinity, c) purity, d) porosity and e) thickness 
a)

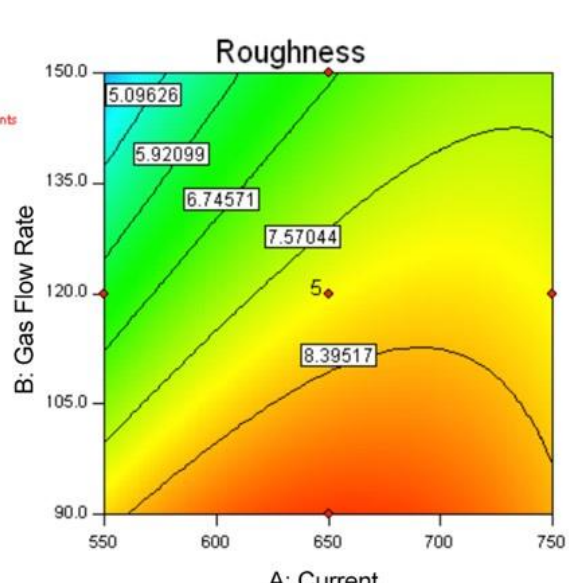

c)

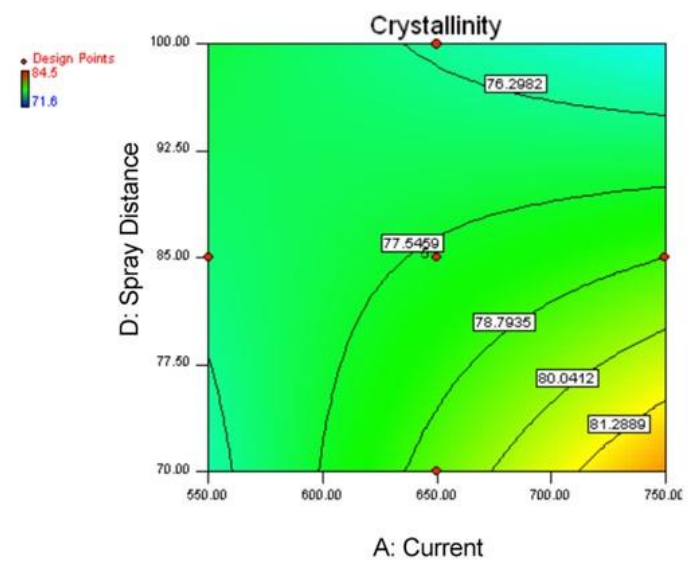

b)

$\dot{\bigsqcup}_{71.6}^{84.5}$

d)
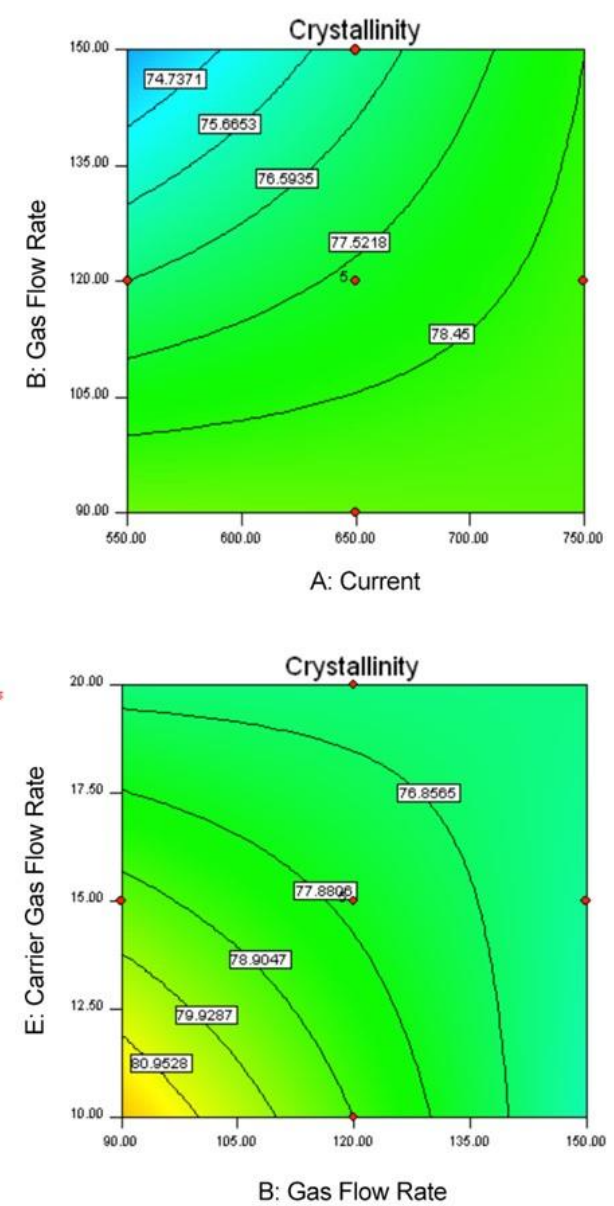

Figure 3: Interaction effect of a) current * gas flow rate on roughness b) current * gas flow rate on crystallinity c) current * spray distance on crystallinity and d) gas flow rate * carrier gas flow rate on crystallinity 

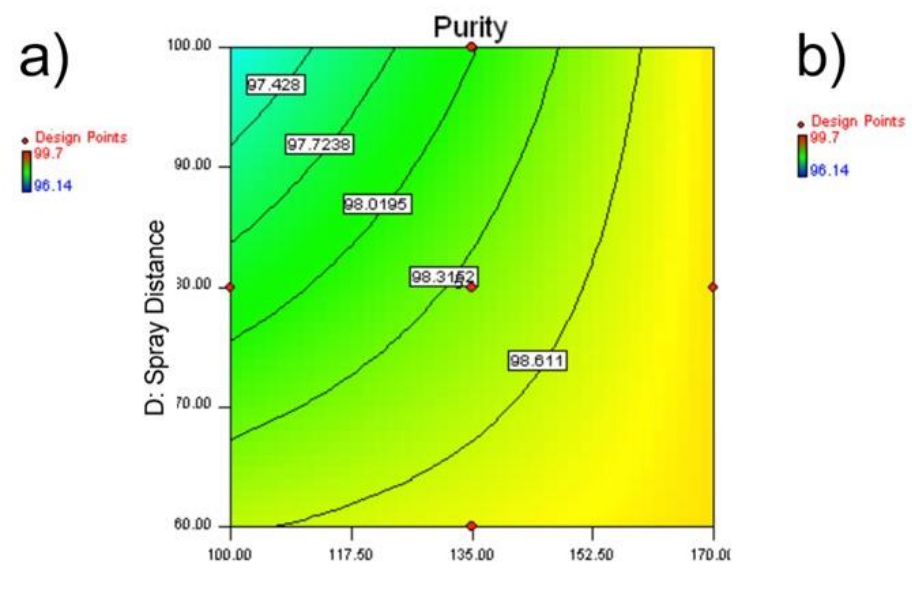

C)

B: Gas Flow Rate

d)
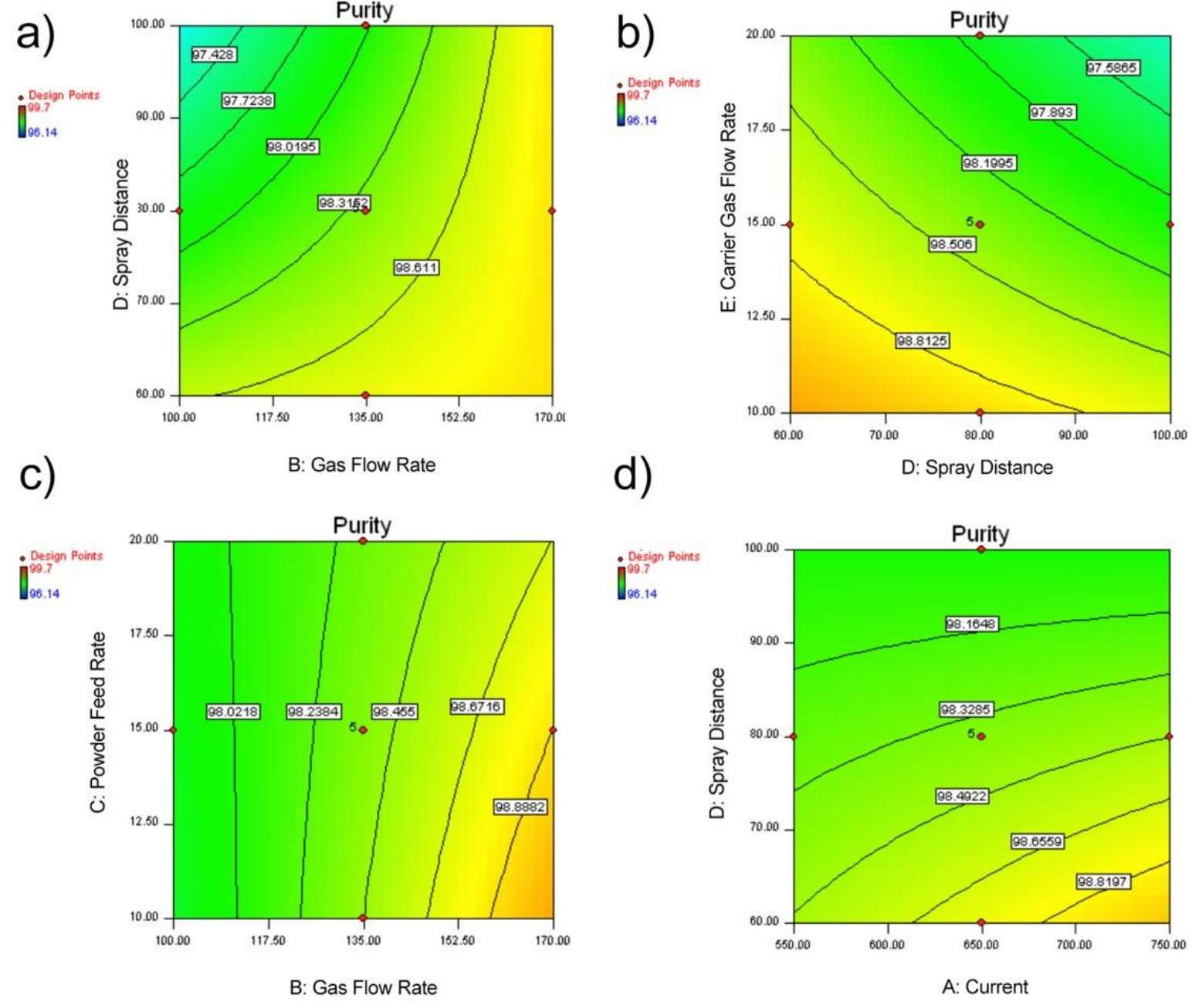

Figure 4: Interaction effect of a) gas flow rate * spray distance b) spray distance * carrier gas flow rate c) gas flow rate * powder feed rate and d) current * spray distance on purity 

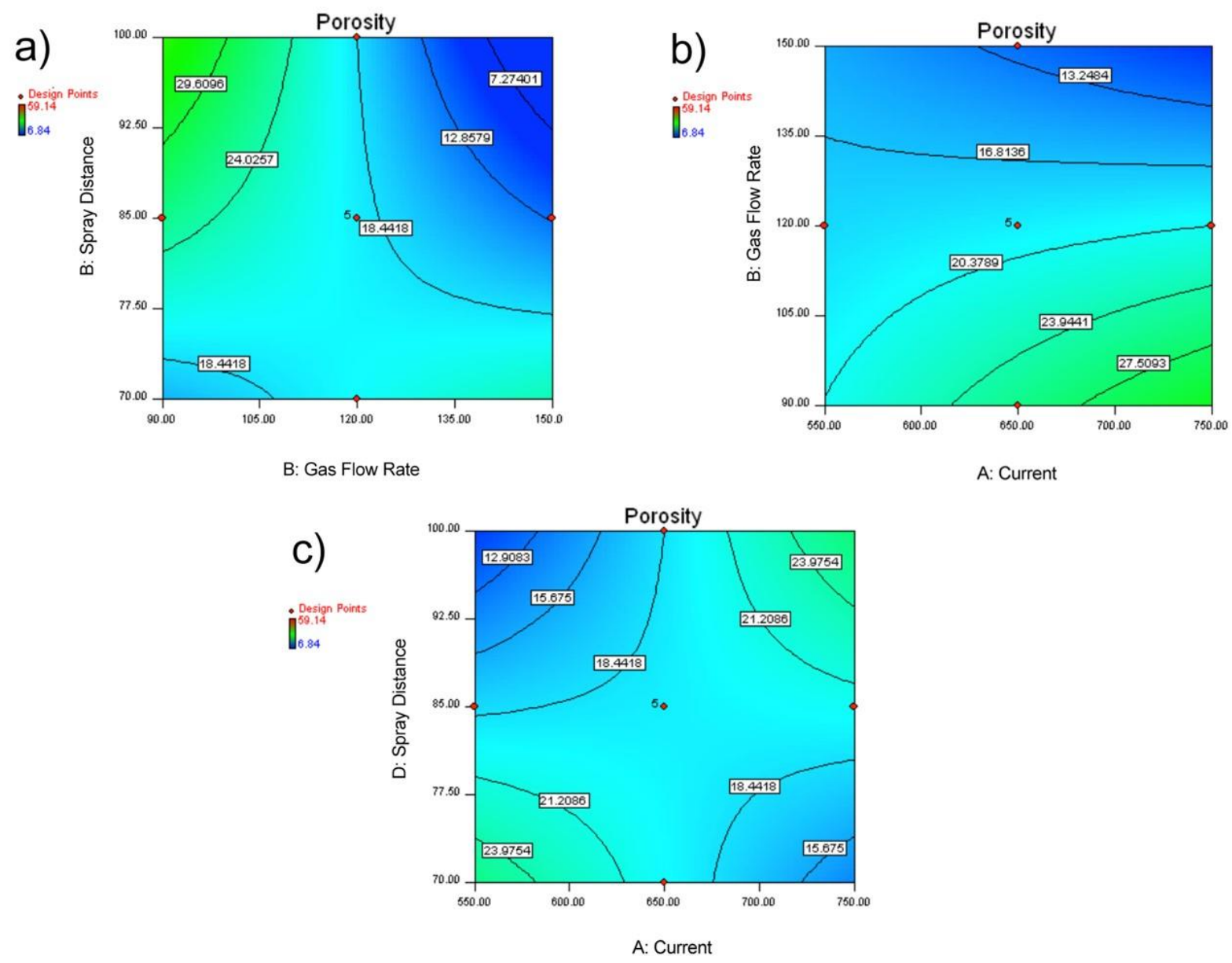

Figure 5: Interaction effect of a) gas flow rate * spray distance b) current $*$ gas flow rate and c) current $*$ spray distance on porosity 

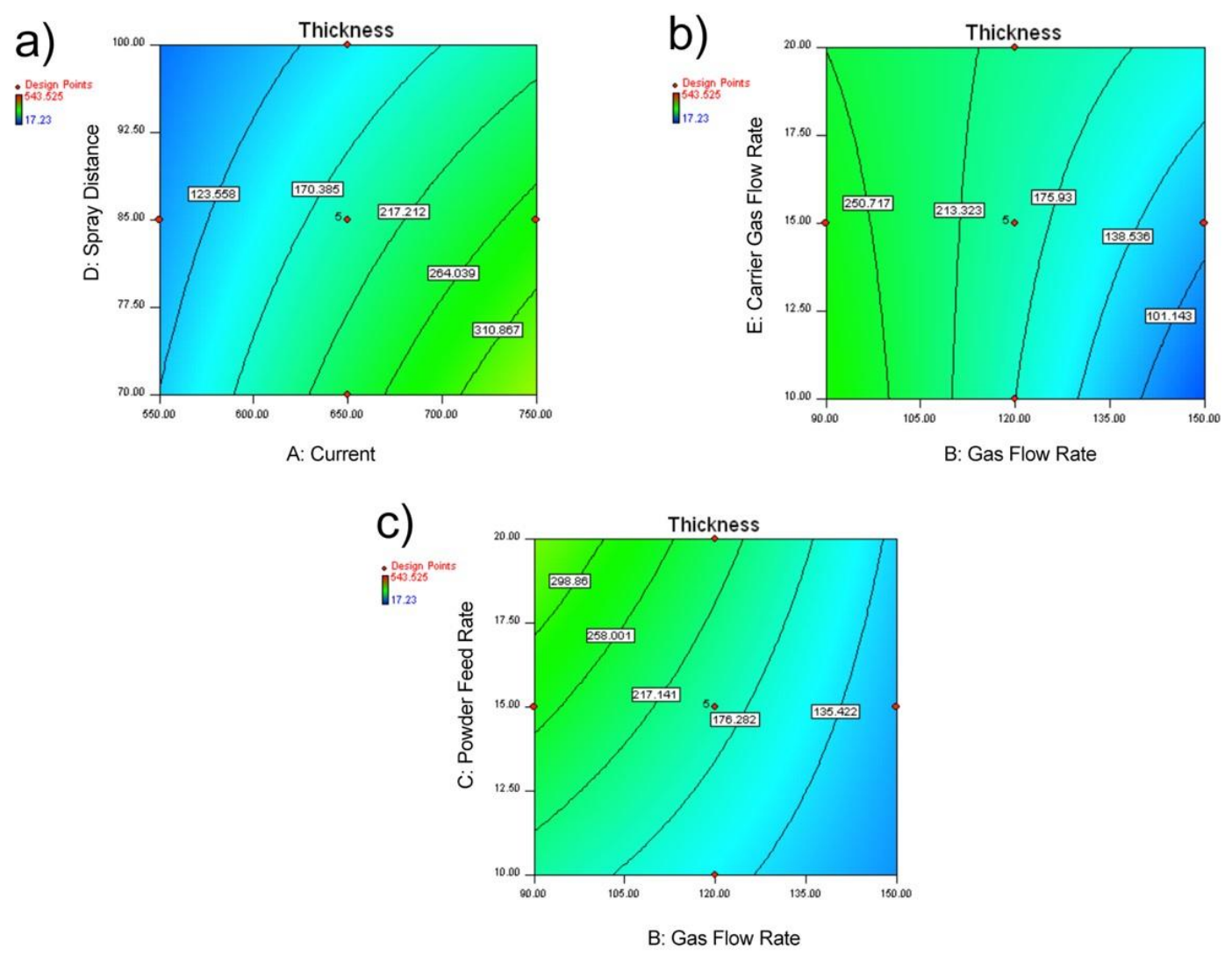

Figure 6: Interaction effect of a) current * spray distance b) gas flow rate * carrier gas flow rate and c) gas flow rate * powder feed rate on thickness

a)

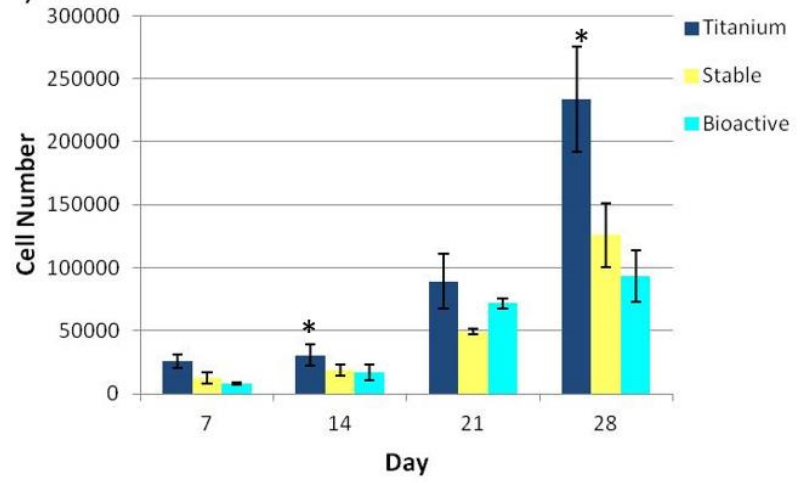

b)

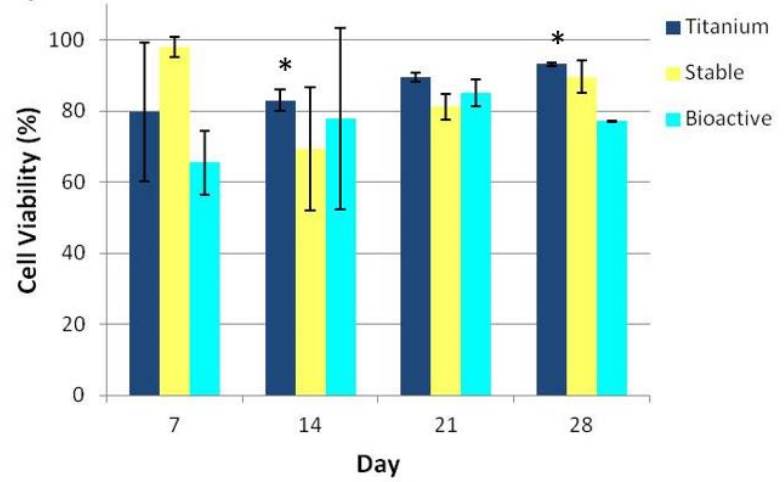

Figure 7: Cell proliferation and cell viability on the titanium control, stable coating and bioactive coating at day $7,14,21$ and $28(*$ indicates $\mathrm{p}<0.1)$ 

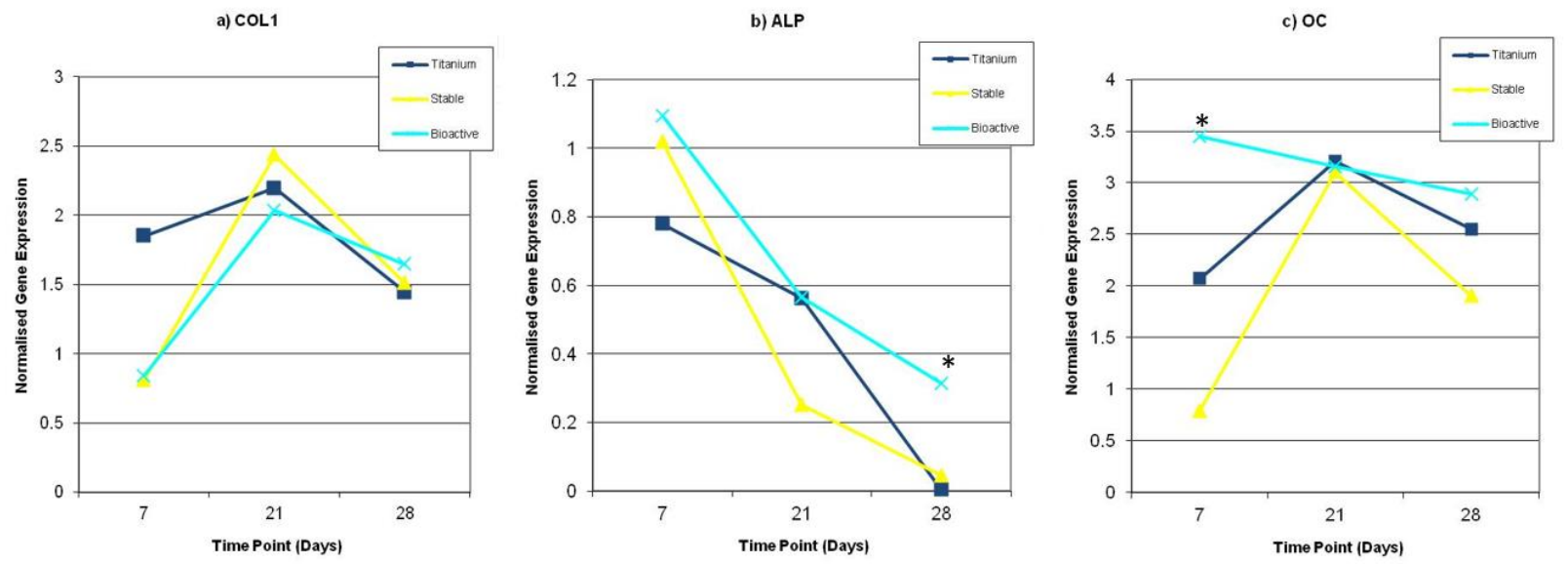

Figure 8: Gene expression profiles for a) collagen 1 (COL1), b) alkaline phosphatase (ALP) and c) osteocalcin $(\mathrm{OC})$ on the titanium control, stable coating and bioactive coating at day 7,21 and 28 (* indicates $\mathrm{p}<0.05)$ 